\title{
EJA: UMA APRENDIZAGEM POSSÍVEL
}

\author{
Rosângela das Neves Leite ${ }^{1}$
}

RESUMO: Muitos são os motivos que impedem alguém de frequentar a escola, mas maiores que eles são os motivos para voltar a estudar. Seja pela necessidade de um emprego melhor ou apenas pelo prazer de ler e entender algo que está escrito, estudar é essencial atualmente e sempre há tempo para ir em busca dos sonhos e refazer a vida. $\mathrm{O}$ acesso à Educação é fundamental para que todos possam intervir de modo consciente na esfera pública, participar plenamente da vida cultural e contribuir com seu trabalho para a satisfação das necessidades básicas e a melhoria das condições de vida da sociedade. E, embora, o conhecimento deva ser construído a partir das vivências do aluno, é importante apresentar ao aluno argumentos para que este mude de paradigma e busque a leitura, o debate e a reconstrução do eu sem desqualificar seus saberes. Freire diz algo interessante: "Ai de nós se não sonharmos sonhos possíveis." Mister se faz evidenciar que a EJA é uma educação possível e capaz de mudar significativamente a vida de uma pessoa, permitindolhe reescrever sua história de vida.

Palavras-chave: Educação de Jovens e Adultos. Aprendizagem. Vivências do aluno. Mudança.

ABSTRACT: There are many reasons that prevent someone from attending school, but bigger are the reasons for going back to school. Whether because of the need for a better job or just for the pleasure of reading and understanding something that is written, studying is essential these days and there is always time to pursue your dreams and rebuild your life. Access to education is essential for everyone to consciously intervene in the public sphere, participate fully in cultural life and contribute with their work to satisfy basic needs and improve society's living conditions. And, although knowledge must be built from the student's experiences, it is important to present arguments to the student so that they can change their paradigm and seek reading, debate and the reconstruction of the self without disqualifying their knowledge. Freire says something interesting: "Woe to us if we don't dream possible dreams." Mister makes it clear that EJA is an education that is possible and capable of significantly changing a person's life, allowing them to rewrite their life story.

Keywords: Youth and Adult Education. Learning. Student experiences. Change.

\footnotetext{
I Graduada em Pedagogia pela Faculdade Norte do Paraná (UNOPAR), Graduada em Ciências Naturais (FACIBA), Pós-Graduada em Educação de Jovens e Adultos (GAMA FILHO), Pós - Graduada em Gestão Escolar (GAMA FILHO). Estudante do curso de Mestrado (INTEGRALIZE). Atua como docente da rede municipal de Esplanada e Entre - Rios, cidades do estado da Bahia. Email: rleite792@gmail.com
} 


\section{INTRODUÇÃO}

Atualmente a EJA é reconhecida por sua identidade, sendo o seu público, jovens e adolescentes, que estão em uma faixa etária com defasagem ou que estão empregados, o que pode ser compreendido através do contexto de escolarização sofrido por essa modalidade, o que implica que a reflexão sobre a história da Educação de Jovens e Adultos pode ajudar a compreender suas mazelas e até mesmo contribuir para uma possível transformação.

A importância da EJA vai além da lógica do mercado. Não é só para qualificar mão de obra para acelerar o desenvolvimento do país. É especialmente importante para a formação da cidadania. A educação estimula a participação efetiva das pessoas na vida política e cultural, incentiva a relação positiva entre as gerações.

São os jovens e os adultos que votam e educam as crianças. A lógica de investir nas novas gerações e esperar os mais velhos morrerem é equivocada.

É preciso repensar as políticas públicas, colocar em debate nos fóruns de EJA e demais espaços de discussão, para que sejam cobrados investimentos financeiros e ações políticas efetivamente condizentes com a realidade. A escola precisa estar atenta às necessidades, desejos e características dos representantes de todo o grupo social constituído por alunos da EJA, quanto à necessidade de uma educação que atenda não só as demandas da sociedade, mas a deles próprios, como sujeitos imersos na sociedade contemporânea. Isso se traduz numa escola cujos princípios político-pedagógicos devam estar o mais próximo possível das dinâmicas que caracterizam essa sociedade. Esses alunos precisam, dentre outras coisas, desenvolver habilidades e competências a fim de utilizar as tecnologias em sentido mais amplo: estabelecer relações com o outro, construir conhecimentos, se comunicar, realizar das mais simples às mais complexas atividades por meio dessas tecnologias presentes no cotidiano, como também atuar ativamente como cidadão e assim ser capaz de integrar o mercado de trabalho e provocar transformações na sociedade.

E, embora, o conhecimento deva ser construído a partir das vivências do aluno, é importante apresentar ao aluno argumentos para que este mude de paradigma e busque a leitura, o debate e a reconstrução do eu sem desqualificar seus saberes. Com relação às 

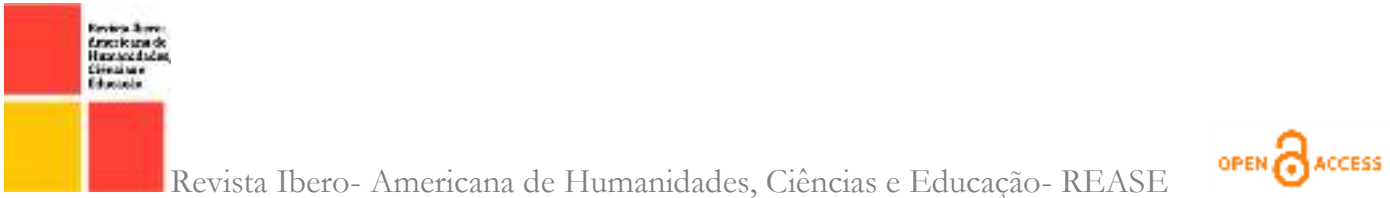

perspectivas dos educandos e seus projetos de vida, a EJA poderá colaborar para que eles ampliem seus conhecimentos de forma crítica, viabilizando a reflexão pela busca dos direitos de melhoria de sua qualidade de vida.

Freire quando começou a trabalhar a educação de jovens e adultos estava preocupado em que o ser humano se libertasse, para que fosse, mas feliz, crescesse, que seguisse em frente e a escola seria um dos espaços em que os educandos desenvolveriam a capacidade de pensar, ler, interpretar e reinventar o seu mundo, por meio da atividade reflexiva.

A ação da escola será de mediação entre o educando e os saberes, de forma que ele assimile conhecimentos como recursos de transformação de sua realidade. $O$ tempo que um educando participa da EJA tem valor próprio e significativo e, portanto, a escola deve superar o ensino de caráter enciclopédico, centrado mais na quantidade de informações do que na relação qualitativa com o conhecimento. Quanto aos conteúdos específicos de cada disciplina, deverão estar articulados à realidade, considerando sua dimensão sócio histórica, articulada ao mundo do trabalho, à ciência, às novas tecnologias.

\section{EJA:QUE PÚBLICO É ESSE?}

A andragogia, do grego ("andros" - adulto e "gogos" - educar) se constitui como a ciência voltada ao ensino de adultos. Ao se pensar em educação de adultos, precisamos ter como princípio a ideia de que algumas particularidades precisam ser respeitadas e, por essa razão, o currículo deve ser pensado em função das necessidades deste perfil singular de estudante.

A Educação de Jovens e Adultos (EJA) constitui-se em forma de ensino oferecida pela rede pública do Brasil, objetivando desenvolver o ensino fundamental e médio, para as pessoas que não tiveram acesso ou não concluíram os estudos da idade certa. $O$ aluno da EJA traz um histórico de insucessos e desafios na sua vida escolar. Para que aconteçam melhorias junto ao alunado da EJA é necessário criar possibilidades para que os discentes sintam-se envolvidos no processo de ensino e que estes sejam norteados por práticas que possibilitem a inclusão educacional e social. Para isto, os trabalhos educativos com jovens, adultos e idosos devem estar alicerçados com práticas que desenvolvam a permanência do 

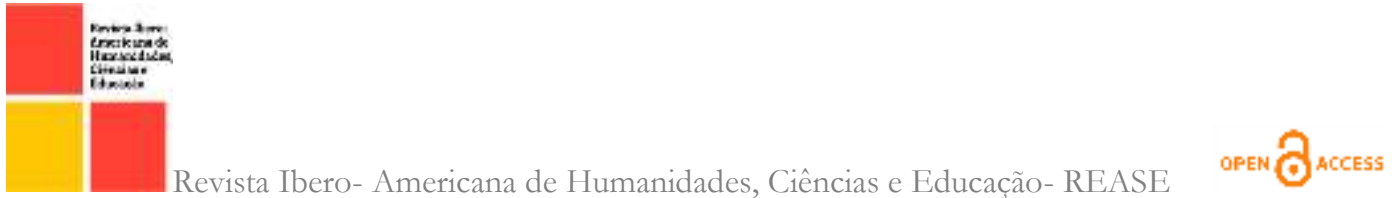

educando na escola, permitindo o seu desenvolvimento em múltiplas dimensões e fazendo com os mesmos se preparem para novos desafios que surgem na sua vida diária.

A UNESCO utiliza do nome Educação de Adultos, para referir-se a uma área especializada da educação, o que é correto em partes, mas não deve ser desassociada da educação global. Já termo educação não formal que vem sendo utilizado principalmente pelos EUA para referir-se à educação de adultos que se desenvolve nos países de Terceiro Mundo que é geralmente vinculada aos projetos de educação comunitária.

No Brasil, pessoas entre 4 e 17 anos são obrigadas por lei a estudar. Quem não se encaixa nessa faixa etária ou está numa idade muito defasada em relação ao ano que deveria estar cursando - como um jovem de I6 anos que ainda está nos primeiros anos do fundamental - pode contar com a Educação de Jovens e Adultos (EJA). Hoje, a EJA é a alternativa oferecida pelo Estado para dar educação àqueles que não tiveram acesso ou desistiram da escola. $\mathrm{O}$ sistema de educação para adultos é de extrema importância para a formação de cidadãos, conscientes de seus deveres e direitos, e para a economia do país.

O ensino de jovens e adultos é quase sempre visto como uma educação inferior às demais etapas da educação. No entanto, é cabível dizer que se trata de um método de ensino que se adapta à rotina dos indivíduos e assim requer uma atenção especial, principalmente no preparo do corpo docente, na estrutura da escola e no conteúdo aplicado. Por ser uma modalidade que enfrenta desafios além da educação regular, tem sido pauta nas discussões e nos planejamentos pedagógicos do passado e da atualidade. Acreditamos aqui que todo o ser social tem seu grau de letramento individual, isto por que, não podemos deixar de considerar o letramento fora da escola. Este indivíduo busca o letramento dentro da escola, mas não deixou de adquirir o seu letramento fora dela.

\footnotetext{
A falsa caridade, da qual decorre a mão estendida do "demitido da vida", medroso e inseguro, esmagado e vencido. Mão estendida e trêmula dos esfarrapados do mundo, dos "condenados da terra". A grande generosidade está em lutar para que, cada vez mais, estas mãos, sejam de homens ou de povos, se estendam menos em gestos de súplica. Súplicas de Humildes a poderosos. E se vão fazendo, cada vez mais, mãos humanas que trabalhem e transformem o mundo. (FREIRE, 1997:42).
}

Por isso, o novo conceito de educação libertadora proposta por Freire, diz que os conhecimentos adquiridos por todos os educandos devem ser sempre considerados, pois, somente se conhece o que é bom quando se conhece o ruim. Cabe aos professores perceber 
a necessidade real de cada aluno e de cada turma e assim poder andar com seus alunos, juntos, em um caminho repleto de conhecimentos e boas experiências.

De acordo com Paraná (2006, p. 27), a Educação de Jovens e Adultos (EJA) é o segmento especialmente criado para atender aos estudantes que trabalham. A meta dessa modalidade educacional é "o compromisso com a formação humana e com o acesso à cultura geral, de modo que os educandos aprimorem sua consciência crítica, e adotem atitudes éticas e compromisso político, para o desenvolvimento da sua autonomia intelectual".

A educação de jovens e adultos, visando à transformação necessária, com o objetivo de cumprir de maneira satisfatória sua formação de preparar jovens e adultos para o exercício da cidadania e para o mundo do trabalho, necessita de mudanças significativas. A nova concepção deve fazer com que todos possam descobrir, reanimar e fortalecer seu potencial criativo. Isso supõe que se ultrapasse a visão puramente instrumental de educação, considerada como a via obrigatória para obter certos resultados (saber fazer, aquisição de capacidades diversas, fins de ordem econômica) e se passe a considerá-la em toda sua plenitude: como realização da pessoa que, na sua totalidade, aprende a ser.

\footnotetext{
Hoje, mais que nunca, a educação e a aprendizagem dos adultos constituem a chave indispensável para liberar as forças criativas das pessoas, dos movimentos sociais e das nações. A paz, a justiça, a autoconfiança, o desenvolvimento econômico, a coesão social e a solidariedade continuam a ser metas e obrigações indispensáveis que terão de ser perseguidas, reforçadas por meio da educação e da aprendizagem dos adultos." (V CONFINTEA, 2003).
}

Os objetivos da EJA priorizam a formação de cidadãos para sociedades democráticas, através de um sistema educacional de qualidade, orientado para o resgate dos valores da cidadania. O principal objetivo da Educação de Jovens e Adultos é de auxiliar cada individuo a tornar-se tudo aquilo que ele tem capacidade para ser.

\section{APRENDIZAGEM SIM, POR QUE NÃO?}

Uma das preocupações de Paulo Freire era com o educador e sua prática diante do ensino da EJA. Os educadores que se comprometem com a Educação de Jovens e Adultos devem buscar métodos que facilitem as necessidades destes alunos. Compreendendo suas dificuldades, em relação às outras modalidades de ensino. Buscar conhecer a realidade 
destes educandos, como mostra este pensamento: "Não há razão para se envergonhar de por desconhecer algo, testemunhar a abertura dos outros, a disponibilidade curiosa à vida, a seus desafios, são saberes necessários à prática educativa” (FREIRE, 1999, P. 153).

Outro fator importante para essa perspectiva educacional está na utilização de mecanismos do conhecimento empírico para que sejam trabalhadas as ferramentas de ensino, ou seja, observar a comunidade onde estão inseridos e o público que precisa ser atingido. Isso reflete significativamente na educação, não apenas na modalidade para jovens e adultos, mas em todas as etapas. Junto a isso, o convívio e o bom relacionamento entre educador e educandos constituem bons resultados para que se atinjam os objetivos das propostas educacionais.

Para Freire (1997), “... quem ensina aprende ao ensinar. E quem aprende ensina ao aprender”. Ou seja, a educação de adultos é capaz de enriquecer o intelecto de aprendizagem, desenvolvendo as habilidades humanas para que se tenha uma sociedade cada vez mais humana e justa. A educação ocorre em todo lugar e a todo momento, seja na escola, no meio doméstico ou na rua, sendo capaz de tornar a sociedade "multicultural".

\section{CONSIDERAÇÕES FINAIS}

$\mathrm{Na}$ EJA, é preciso romper com a ideia de educação compensatória que prevaleceu por muitos anos. Deve-se deixar de restringir à compensação da educação básica, não adquirida no passado, para responder às múltiplas necessidades formativas que os indivíduos têm no presente e terão no futuro. É necessário que o educador conheça seus alunos a fim de saber quais são suas demandas, expectativas, vivências e a diversidade cultural que abriga este grupo, para que não ocorra a infantilização dos adultos, o que, em muitos locais, acontece, por não se entender a complexa dimensão da educação de adultos.

A primeira característica comum a essas iniciativas é o reconhecimento, o acolhimento e a valorização da diversidade dos educandos da EJA, pois antes de serem alunos, esses jovens e adultos são portadores de identidades de classe, gênero, raça e geração. Suas trajetórias de vida são marcadas pela região de origem, pela vivência rural ou urbana, pela migração, pelo trabalho, pela família, pela religião e, em alguns casos, pela condição de portadores de necessidades especiais. Compromisso, entusiasmo e 
competência são ingredientes necessários às equipes pedagógicas em qualquer modalidade do ensino, mas o impacto de sua atuação depende em grande medida das condições em que realizam o trabalho educativo. Instalações físicas e financiamentos adequados, valorização dos profissionais e assistência aos estudantes com alimentação, transporte e material são pré-requisitos para uma EJA mais relevante. Apesar de óbvias, essas condições merecem atenção, tendo em vista a precariedade de alguns serviços educativos.

Um ser pensante, e autônomo: é aquele aluno que pensa, tem criticidade e opinião própria. É o aluno que tem suas experiências e conhecimentos respeitados pelo professor. Ele não recebe depósitos de conhecimentos e conteúdos, aprende a respeitar opiniões e impõe respeito as suas, é capaz de construir um conhecimento rico com toda a sala de aula, além de ajudar o professor no ato mais importante; o de aprender de fato tudo que lhe é passado. Este professor por sua vez, é o questionador, o que desperta o interesse do aluno em enxergar as coisas da maneira correta, além de aumentar a sede de seus alunos em aprender. É um profissional inteligente e ao mesmo tempo inquieto que só fica satisfeito quando todos os seus alunos conseguem ser de fato autônomos em suas ideias e em seus pensamentos.

Freire diz algo interessante: "Ai de nós se não sonharmos sonhos possíveis.” Mister se faz evidenciar que a EJA é uma educação possível e capaz de mudar significativamente a vida de uma pessoa, permitindo-lhe reescrever sua história de vida.

\section{REFERÊNCIAS}

ALVES, Rubem. Conversas com quem gosta de ensinar. 28 ed. São Paulo: Cortez, 19993.

ARROYO, M. G. Educação de jovens e adultos: um campo de direitos e de responsabilidade pública. In: SOARES, L. J. G.: GIOVANETTI, M.; GOMES, N.L. Diálogos na Educação de Jovens e Adultos. Belo Horizonte: Autêntica, I edição 2005a, p. 19-50.

BÁRBARA, Maristela Miranda. Contribuições da CUT para uma educação emancipadora. In: UNESCO. Construção coletiva: contribuições à educação de jovens e adultos. v. 3 . Brasília, 2005.

BRASIL. MEC. Lei de Diretrizes e Bases da Educação. Disponível em: 〈http://www.mec.gov.br>. Acesso em: I2 de abril de 2010. 


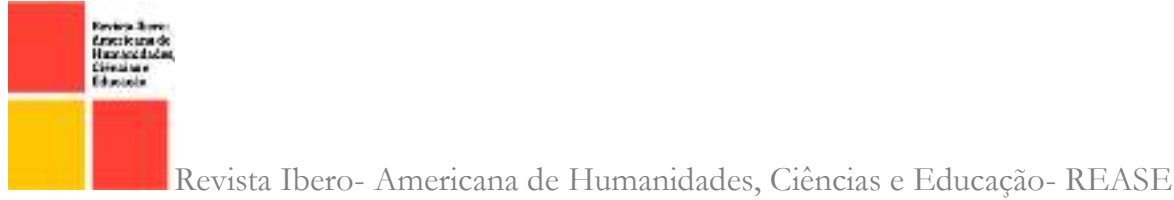

. Plano Nacional de Educação. Disponível em: 〈http://www.mec.gov.br〉. Acesso em: 12 de abril de 2010.

. Lei de Diretrizes e Bases da Educação no 5692 de Ir.08.71, capítulo IV. Ensino Supletivo. Legislação do Ensino Supletivo, MEC, DFU, Departamento de Documentação e Divulgação, Brasília, 1974 .

. PARECER no 699/7I. Regulamenta o capítulo IV da Lei 5.692/7I. o6 de julho de 1972. Constituição Federal de Educação. Rio de Janeiro.

- Secretaria de Educação Fundamental. Parâmetros Curriculares Nacionais: Terceiro e quarto ciclos; Apresentação dos temas transversais. Brasília: MEC /SEF, I998, [Versão disponibilizada na internet pelo Sindicato das Escolas Particulares de Santa Catarina (Sinepe/SC):www.sinepe-sc.org.br/5a8tt.html].

DEMO, Pedro. Metodologia do conhecimento científico. São Paulo: Atlas, 2000.

DI PIERRO, M. C.; JOIA, O.; RIBEIRO, V. M. Visões da educação de jovens e adultos no Brasil. Cadernos Cedes, ano XXI, no 55, novembro/200I. Disponível em: Acesso: 2I de set. de 2009. DI PIERRO, M. C. Nota sobre a redefinição da identidade das políticas públicas de educação de jovens e adultos no Brasil. Educação e Sociedade. Campinas, vol. 26, n. 92, p. 1115-II69, Especial out. 2005.

FREIRE, Paulo. A importância do ato de ler em três artigos que se completam. São Paulo: Ed. Cortez, 2009.

Educação de Adultos, algumas reflexões. In. GADOTTI, Moacir; ROMÂO, José E. (Orgs.) Educação de jovens e adultos: teoria, prática e proposta. 6 ed. São Paulo: Cortez, 2003.

Pedagogia da autonomia: Saberes necessários à prática educativa. 35. Ed. São Paulo: Paz e terra, 1999.

D’Água, 1997.

Professora sim, tia não: cartas a quem ousa ensinar. São Paulo: Olho

. Pedagogia do Oprimido. 9. ed. Rio de Janeiro: Paz e Terra, I98I.

HADDAD, Sérgio. Tendências atuais na educação de jovens e adultos. Em Aberto, Brasília: ano II, no 56, out/dez. 1992.

A educação de pessoas jovens e adultas e a nova LDB. p.io6-i22. In: BRZEZINSKI, Iria (org.). LDB interpretada: diversos olhares se entrecruzam. São Paulo: Cortez, 1997.

JOSGRILBERT, Maria de Fátima V. Paulo Freire e a educação de jovens e adultos. Disponível em 〈http://www.scribd.com/doc/15818538/Paulo-Freire-e-aeducacao-dejovens-e-adultos> Acesso em 02.out.2010. 
OLIVEIRA, Marta Kohl de. Jovens e Adultos como Sujeitos de Conhecimento e Aprendizagem. Revista Brasileira de Educação, Set./Dez.1999, n. 12, p. 59-73.

PAIVA, J. Educação de Jovens e Adultos: continuar e aprender por toda a vida. 2003. Disponível em: Acesso: i6 de nov. de 20I6. RIBEIRO, V. M. M. Educação de jovens e adultos: novos leitores, novas leituras. Campinas, SP: Mercado de Letras, ALB, São Paulo: Ação Educativa, 20or.

PARANÁ. Secretaria de Estado da Educação. Superintendência da Educação. Diretrizes curriculares da educação de jovens e adultos. Curitiba, 2006. Disponível em 〈http://www.diaadia.pr.gov.br/arquivos/File/DCE_EJA2print_finalizado.pdf $>$ Acesso em 09.out.2010.

PILETTI, Nelson e PILETTI, Claudino. História da educação. 2. ed. São Paulo: Ática, I99I.

PINTO, Álvaro Vieira. Sete lições sobre educação de adultos. II ed. São Paulo: Cortez, 2000.

UNESCO. Educação: um tesouro a descobrir. Relatório para a UNESCO da Comissão Internacional sobre Educação para o século XXI. Tradução portuguesa. Rio Tinto: Edições ASA, 1996.

V CONFERENNCIA INTERNACIONAL SOBRE EDUCAÇÃO DE ADULTOS. (VCONFINTEA: 1997: Hamburgo, Alemanha). Declaração de Hamburgo: agenda para o futuro. Brasília: SESI/UNESCO, 1999. 